\title{
Probabilistic Impact Assessment of Low Carbon Technologies in LV Distribution Systems
}

\author{
Alejandro Navarro-Espinosa, Graduate Student Member, IEEE, \\ and Luis F. Ochoa, Senior Member, IEEE
}

\begin{abstract}
Residential-scale low carbon technologies (LCTs) can help decarbonizing our economies but can also lead to technical issues, particularly in low voltage $(\mathrm{LV})$ distribution systems. To quantify these problems this work proposes a Probabilistic Impact Assessment methodology. First, realistic 5-minutes timeseries daily profiles are produced for photovoltaic panels, electric heat pumps, electric vehicles and micro combined heat and power units. Then, to cater for the uncertainties of LCTs (size, location, behavior), a Monte Carlo analysis is carried out considering 100 simulations for different penetration levels (percentage of houses with a LCT). This methodology is applied to 128 real UK $L V$ feeders showing that about half of them can have voltage and/or congestion issues at some penetration of LCTs. Furthermore, to identify the relationships between the first occurrence of problems and key feeder parameters (e.g., length, number of customers), a correlation analysis is developed per LCT. Crucially, these results can be translated into lookup tables to help Distribution Network Operators in producing preliminary estimates of the LCT hosting capacity of a given feeder.
\end{abstract}

Index Terms - Distributed generation, electric heat pumps, electric vehicles, low carbon technologies, low voltage networks, micro combined heat and power, photovoltaic systems, power distribution.

\section{INTRODUCTION}

$\mathrm{T}$ HE reduction of carbon emissions is a challenge today. As a result, many governments are introducing targets to decrease these emissions. For instance, by 2020 the EU has committed to have $20 \%$ of their energy demand sourced by renewables [1], this means about $30 \%$ of the electricity demand to be met by renewables in the UK [2]. Thus, the adoption of low carbon technologies (LCTs) by the domestic customers has been encouraged. These are related to distributed generation, such as photovoltaic systems (PVs), electrothermal technologies, such as electric heat pumps (EHPs) and micro combined heat and power units ( $\mu \mathrm{CHPs})$, and transport electrification, such as electric vehicles (EVs).

Given that domestic customers are connected to low voltage (LV) distribution systems (RMS voltage < $1 \mathrm{kV}$ [3]); these are the assets facing the first impacts due to the penetrations of LCTs. Hence, to assess the extent of these effects on the performance of residential LV circuits, a Probabilistic Impact

This work has partly been funded by ENWL, UK, through the Ofgem's Low Carbon Networks Fund Tier 1 Project "LV Network Solutions", 20112014. A. Navarro-Espinosa and L.F. Ochoa are with the School of Electrical and Electronic Engineering, The University of Manchester, Manchester M13 9PL, UK. (e-mails: alejandro.navarroespinosa@manchester.ac.uk and luis_ochoa@ieee.org).
Assessment methodology is proposed in this work considering four LCTs: PVs, EHPs, $\mu$ CHPs and EVs.

Many studies investigating the effects of these LCTs on LV distribution systems consider generic [4], [5], [6], or American-style circuits [7], [8], [9]. However, findings using the former cannot necessarily provide the LCT hosting capacity of real ones. Similarly, findings considering American-style LV systems, typically with a few customers per transformer, cannot be extended to those using European-style designs (from dozens to hundreds of customers per transformer). The latter are also known as LV networks.

In terms of small-scale generation, in [7], a USA distribution system is studied considering only a snapshot approach (maximum generation and minimum load) but carrying out a Monte Carlo analysis that caters for the uncertainty of generation location and size. A similar snapshot/probabilistic approach is presented in [8] where a Canadian residential feeder is analyzed in the presence of PV systems. A time-series approach (periods of $15 \mathrm{~min}$ ) is adopted in [10] where different PV cases are analyzed considering yearly profiles but only four real Belgian LV feeders. The time-varying impacts of PV systems are also investigated in [11] using real smart meter data from Belgium, however the study is limited to a generic $\mathrm{LV}$ network. Finally, the voltage impacts of PV and $\mu \mathrm{CHP}$ were investigated in [12] using four UK LV networks. This particular work considered a time-series approach, i.e., minute-by-minute load and generation profiles.

Regarding electro thermal technologies, the Monte Carlo approach was adopted in [4] to study the effects of location and size of a single CHP plant in a generic LV network considering multiple snapshots of load and generation. The impacts of EHPs were quantified in [13] and [14] using generic networks but adopting time-series simulations and probabilistic and deterministic approaches, respectively.

Impact studies of EVs on LV networks can also been found in the literature considering hybrid (battery and combustion engine) [5], [9] and fully electric technologies [6], [15]. In [5] and [9], a random selection of load profiles and EV is made adopting data granularities of 15 and 60 minutes, respectively. In both cases, the residential loads are modeled with average profiles. In [15], the EV and load profiles are aggregated at feeder level to quantify only the loading of the transformers, [6] does solve power flows for multiple cases but considering hourly profiles and two generic networks.

From the above review, it is clear that adequate and realistic LV networks need to be considered depending on the geographical region of interest. In addition, catering for the uncer- 
tainties related to location and size of LCTs and residential loads, as well as their time-varying nature, is important to realistically model their behavior [16].

In addition, the analysis of multiple LV feeders should be considered to capture the effects of their diversity, allowing the investigation of the feeders' parameters that could explain the occurrence of technical problems due to LCTs. Once these key parameters are identified, lookup tables can be created for Distribution Network Operators (DNOs) to determine the hosting capacity of a given feeder. To date, however, most of the studies related to LCTs in distribution networks have only analyzed a small number of circuits, e.g., [4], [6], [7] and [8]. Only the study in [17] considers 16 multiple circuits but these correspond to medium voltage (MV) USA-style distribution feeders and the analysis is limited to the use of hourly profiles and deterministic scenarios.

The Probabilistic Impact Assessment methodology proposed in this work embeds the uncertainties related to four LCTs (PV, EHPs, $\mu$ CHP and EVs) via Monte Carlo simulations and different penetration levels (percentage of houses with the LCT). This methodology adopt high resolution profiles and is applied to one real UK LV network (7 feeders) and then extended to 25 real UK LV networks (128 LV feeders).

The rest of the paper is structured as follows. Section II provides an overview of the proposed framework. Section III describes the load and LCT profiles. The Probabilistic Impact Assessment methodology is presented in section IV. Section V illustrates the application of the methodology and section VI explores the probabilistic nature of the results. The impact assessment of 128 feeders is presented in section VII and the corresponding correlation analysis in section VIII. Finally, the main conclusions are drawn in section IX.

\section{Probabilistic Framework OVERview}

To understand the impacts of LCTs on LV networks considering the corresponding locational and behavioral uncertainties, a probabilistic framework is proposed which can be applied to any type of feeder and LCT. Furthermore, for a given set of feeders, this framework provides an approach to create lookup tables to help determining the LCT hosting capacity of feeders with similar characteristics.

Fig. 1 illustrates the proposed framework. Once the models of the LV feeders as well as load and LCT profiles are produced (section III), for a given LCT and for a given feeder, a Monte Carlo simulation is carried out (section IV). This allows managing the complexity from multiple stochastic variables, particularly when adopting realistic feeder, load and LCT models. Multiple individual power flow analyses for each of the LCT penetrations are investigated. For each of individual power flow, locations and profiles of load and the studied LCT are randomly allocated following appropriate distributions. The impact metrics are then quantified and stored for the particular simulation. Finally, based on a multi-feeder correlation analysis (section VIII), feeder parameters can be identified to then produce lookup tables. The application of this framework on a representative set of feeders can provide critical insights that can then be generalized to the corresponding population.

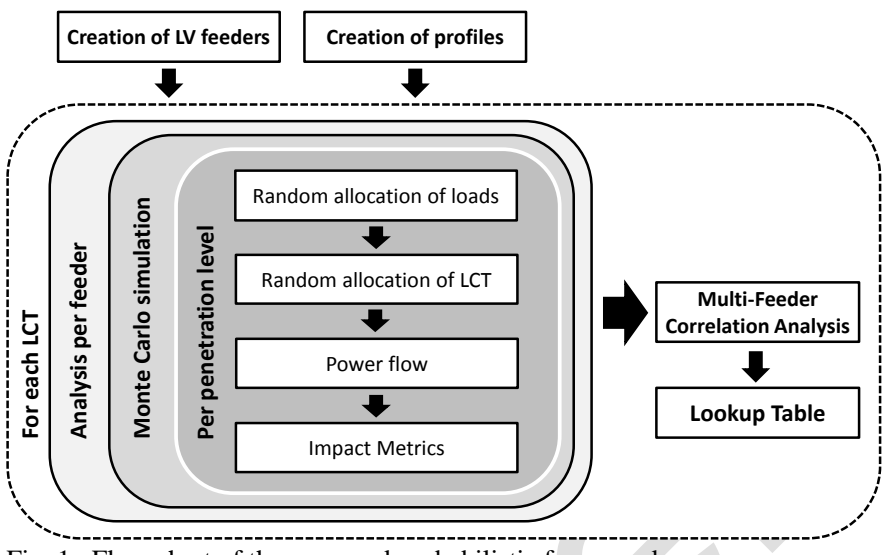

Fig. 1. Flow chart of the proposed probabilistic framework

\section{LOAD AND LCT PROFILES}

To understand the impacts of LCTs on LV networks, the adoption of time-series profiles is required. The profiles used in this work correspond to residential loads, PVs, $\mu$ CHPs, EHPs and EVs. These daily profiles have a resolution of 5 minutes and have been made available in [18]. This granularity is crucial to ensure voltage issues are captured by the European Standard (EN 50160) [19] which requires 10-minutes RMS averages for its compliance assessment. In terms of power factor, residential loads are assumed to have a value of 0.98 (inductive/lagging power factor). All the LCTs are considered to operate at unity power factor. For completeness, other LCT power factors are explored in section VII.

\section{A. Residential Load Profiles}

Individual residential loads are created using the tool presented in [20]. This tool creates realistic 1-minute resolution daily time-series profiles for residential loads based on the behavior of British domestic customers (single-phase connections to the LV network). The adopted profiles have been modified to a resolution of 5 minutes and consider all customers to have access to the gas network for heating purposes.

To mimic the stochastic behavior of the load consumption per household, summer and winter pools each with 2,000 different load profiles were created. The proportion of profiles with a given number of people is based on UK statistics [21]: $29,35,16$ and $20 \%$ for houses with one, two, three and four (or more) persons, respectively. To illustrate the average behavior of residential customers, 100 profiles are chosen as a practical and realistic number in the context of UK LV feeders. Thus, Fig. 2 shows the average profiles considering 100 load profiles for winter and summer weekdays. It can be seen that for winter, the average peak demand is about $1.0 \mathrm{~kW}$, whereas for summer is about $0.8 \mathrm{~kW}$. In terms of energy consumption, these values are 9.1 and $10.6 \mathrm{kWh}$.

\section{B. PV Profiles}

Sun irradiance recorded by the Whitworth Meteorological Observatory in Manchester, UK [22] in 2013 is used. The 30 sunniest days, ranked according to the integral of the daily sun irradiance curve, are identified to capture the most challenging yet realistic scenarios. To translate this data into single-phase PV generation profiles, efficiencies of $15 \%$ and $95 \%$ for the 


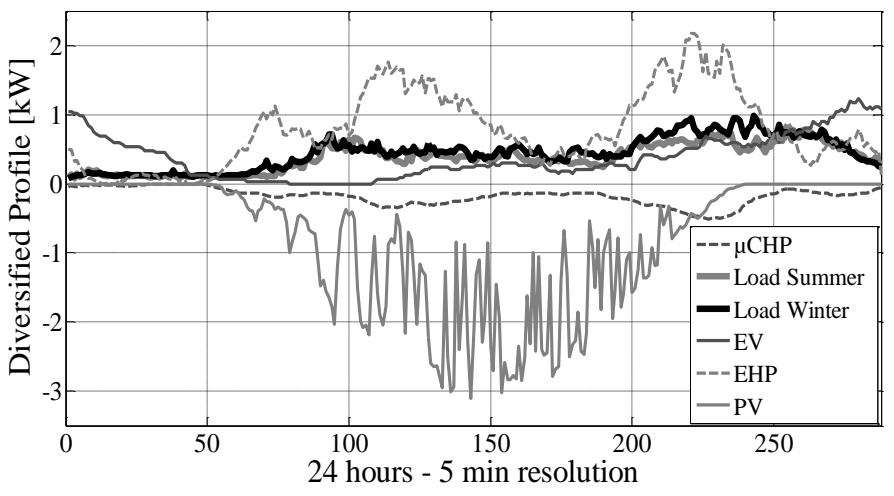

Fig. 2. Average profile for groups of 100 profiles of loads and LCTs

energy conversion process and the inverter are assumed [23].

A pool of 2,000 different PV profiles is produced for each of the selected 30 sun irradiance profiles. Recent statistics [19] are used for a realistic mix of PV sizes: 1, 8, 13, 14, 12 and $37 \%$ of the PV profiles use installed capacities of 1.0, 1.5, 2.0, $2.5,3.0,3.5$ and $4.0 \mathrm{kWp}$, respectively. For a given LV network and simulation, here it is assumed that all households receive the same sun irradiance. Fig. 2 shows the average profile considering $100 \mathrm{PVs}$ from one of the PV pools as a negative curve (power injection), showing a maximum generation of about $3.0 \mathrm{~kW}$ during noon and a production of $19 \mathrm{kWh}$.

\section{EV Profiles}

The statistical analysis presented in [24] from a recent oneyear field trial of EVs in Dublin is used to create the profiles. For this purpose, the probability distributions of connection times and the corresponding energy required are combined to produce the daily behavior of individual EVs considering one charge at home per day. Given that UK residential loads are single phase, EV users are initially expected to mostly adopt slow charging modes at home. Thus, all EVs are assumed to have a battery of $3 \mathrm{~kW}$ and $24 \mathrm{kWh}$ (e.g., Nissan Leaf).

Thus, by using the battery characteristics and the two probability distributions, a pool of 2,000 slow charging residential $\mathrm{EV}$ profiles is created. Fig. 2 indicates the average profile for $100 \mathrm{EV}$ profiles, showing an average peak demand of $1.2 \mathrm{~kW}$ at 21:00. The energy consumption corresponds to $9.1 \mathrm{kWh}$.

\section{D. $\mu$ CHP Profiles}

Real data of $\mu$ CHPs operation from a field trial in the UK [25] has been considered for the creation of profiles. This data provides the electricity generation for different $\mu$ CHPs and the electricity consumption of the houses where these units are installed; all this data has a granularity of 5 minutes. A cold winter day (average of $4^{\circ} \mathrm{C}$ ) is used to investigate the effects when the $\mu$ CHPs will be used the most.

Then, a pool of 2,000 $\mu$ CHP and 2,000 loads is created by randomly shifting the real profiles available from 5 to 30 minutes [13]. For consistency, each $\mu \mathrm{CHP}$ profile is linked directly to a single load profile, i.e., a realistic power export is considered in each simulation. In Fig. 2, the average profile among $100 \mu \mathrm{CHPs}$ is presented as a negative curve (power injection), showing an average maximum generation of 0.5 $\mathrm{kW}$. The energy production is $4.3 \mathrm{kWh}$.

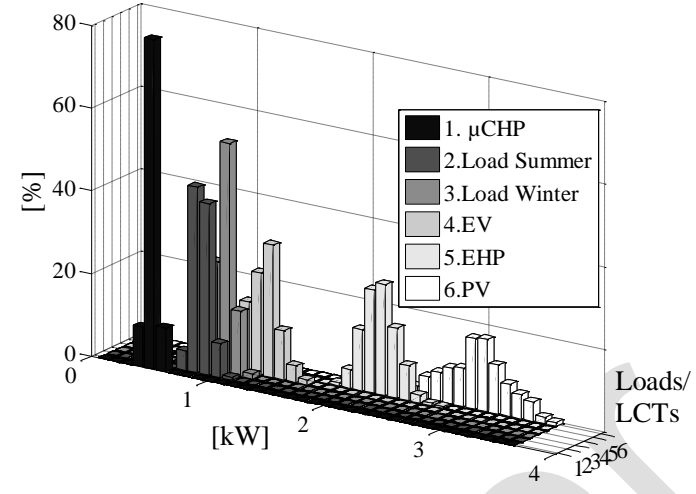

Fig. 3. Histogram of average peak demand for groups of 100 loads and LCTs

\section{E. EHP Profiles}

The creation of EHP profiles is based on the methodology presented in [13]. The household thermal demand from [25] is transformed into EHP electrical demand by using curves from EHP manufacturers [26] (same winter day as the $\mu \mathrm{CHPs}$ ). The technology used here corresponds to Air Source Heat Pump (ASHP) as they can be retrofitted in most houses. The EHP is designed to cover $80 \%$ of the peak thermal load on the coldest day. Thus, if additional heat is required an electric heater is available. The total electricity consumption (EHP plus auxiliary heater) is the one allocated to the EHP profiles.

Similarly to the $\mu$ CHP case, the load profiles are consistent with the heat requirements and therefore with the EHP profile created for each house. Thus, a pool of 2,000 EHPs and the corresponding 2,000 loads is created. As an example, the average demand for 100 EHPs is shown in Fig. 2, indicating an average maximum demand of $2.2 \mathrm{~kW}$ coincident with the average peak demand. The energy consumption is $18.9 \mathrm{kWh}$.

\section{F. Diversified Maximum Demand}

LV networks in the UK, as in most parts of the world, are designed considering a diversified (average) maximum demand per customer (as a fixed value or applying a diversity factor). Therefore, from the planning perspective, it is important to understand the average behavior of LCTs to obtain an initial idea of how LV networks might be affected. To capture the most representative diversified maximum demand for each LCT, different groups of 100 profiles are randomly selected from their corresponding pools. This process is repeated one thousand times for each case extracting the maximum demand from the diversified profile.

Results are organized in histograms in Fig. 3. For the winter load, the diversified maximum demand is between 0.8 and $1.2 \mathrm{~kW}$ (median of $1 \mathrm{~kW}$ ). As for the new loads, the EHP has the largest diversified maximum demand (median of $2.2 \mathrm{~kW}$ ). Its likely coincidence with peak hours during winter means an average total peak demand of $3.2 \mathrm{~kW}$. Depending on the penetration, this can result in voltage or congestion issues. In terms of generation technologies, clearly, PV systems will inject much more than $\mu \mathrm{CHP}$. However, the effect of the former is likely to be seen during minimum demand periods.

It is important to highlight that the average peak values of loads and LCTs are dependent on the number of customers used to produce the corresponding histogram. Furthermore, 
the number of customers will also influence the corresponding simultaneity among those average peak values. Consequently, to adequately cater for the simultaneity among different numbers of customers in a feeder and different LCT penetrations, individual profiles should be adopted.

\section{PRoBABILISTIC IMPACT ASSESSMENT}

\section{A. Methodology}

The Probabilistic Impact Assessment methodology proposed in this work embeds the uncertainties related to the four LCTs presented in section III, in terms of location, size and behavior, via Monte Carlo simulations. Different penetration levels (percentage of houses with the LCT) are investigated each considering 100 simulations. The main steps for a single simulation given a particular feeder, LCT, and penetration level (from 0 to $100 \%$ in steps of $10 \%$ ) are described below. These steps are repeated for each of the 100 simulations.

1. Load profiles from the pool produced in section III are randomly allocated to households in the feeder (note that the pool already considers a realistic distribution of number of people per household). To capture the seasonality of the impacts that different LCTs might bring about, the pool of summer loads is used for the PV cases whereas the winter loads are used for the EV cases. As for the electrothermal technologies, the real electricity consumption data associated with each of the houses is used, thus the coincidence between electricity and heat consumption is fully considered [13].

2. For the analyzed penetration level, the houses to have the corresponding LCT are randomly selected. The LCT profiles are then randomly selected from the pools created in section III. Note that each of these pools already follows different probability distributions to cater for the uncertainties related to their size and behavior.

3. Once the load and LCT profiles are allocated to the households in the feeder, a daily time-series power flow is executed using OpenDSS [27]. The power flow results (i.e., voltage, current and apparent power) are stored for this simulation to be used for the impact assessment.

It is important to highlight that in the proposed methodology the phase connection of the LCT is that of the corresponding house. Therefore, given the stochastic nature of the analysis some simulations could have LCTs allocated in a way that increase the imbalance level, thus resulting in larger voltage rises [28], [29] or drops [30]. The intentional selection of specific phase connections of LCTs was not investigated. Hence, the LCTs are likely to be connected following the actual distribution of customers among the phases. This distribution is shown in Table I for the example network.

\section{B. Impact Metrics}

Given the time-varying nature of LCTs and household demand, the technical impacts will also change throughout the day. Consequently, this should be taken into account when quantifying voltage excursions or congestion issues. For this

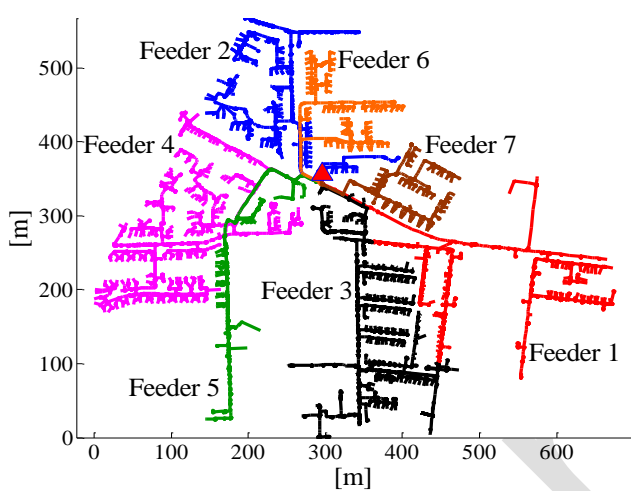

Fig. 4. Topology of the studied LV network

TABLE I

MAIN FEATURES PER FEEDER

\begin{tabular}{c|c|c|c|c|c}
\hline \multirow{2}{*}{ Feeder } & \multirow{2}{*}{$\begin{array}{c}\text { Total } \\
\text { Length }(\mathrm{m})\end{array}$} & \multirow{2}{*}{ Loads } & \multicolumn{3}{|c}{ Distribution of Connections (\%) } \\
\cline { 4 - 6 } & 2,515 & 77 & Phase A & Phase B & Phase C \\
\hline 1 & 2,867 & 107 & 38.9 & 24.1 & 37.0 \\
\hline 2 & 4,249 & 169 & 47.8 & 29.4 & 36.8 \\
\hline 3 & 4,513 & 138 & 30.4 & 34.1 & 26.1 \\
\hline 4 & 1,538 & 23 & 31.4 & 34.3 & 34.5 \\
\hline 5 & 1,652 & 68 & 41.1 & 28.0 & 30.8 \\
\hline 6 & 1,301 & 54 & 36.4 & 32.5 & 31.2 \\
\hline 7 & & & & & \\
\hline
\end{tabular}

purpose, the following metrics are adopted per simulation.

Percentage of customers with voltage problems: This metric takes the daily voltage profile calculated for each customer and checks compliance with the standard BS EN 50160 [3] (customers' voltages must be between 0.9 and 1.1 p.u during $95 \%$ of the time and never below 0.85 or above 1.1 p.u). If a customer is not compliant, then it is considered to have a problem. All the customers with problems are added up and this number is divided by the total number of customers in the feeder. Since the profiles have a resolution of 5 minutes, the daily voltage profiles for each customer are averaged in 10 minutes to make the calculation according to BS EN 50160. Although, the limit in BS EN 50160 is 0.9 p.u., this work uses 0.94 p.u., according to the UK legal requirement [31].

Loading level: At the feeder level, this metric is the hourly maximum current divided by the ampacity of the head of the feeder. At the transformer level, this metric considers the hourly maximum apparent power and the transformer capacity. The current and power at each hour is calculated by averaging the corresponding 5-minute resolution values. This metric provides an insight about the potential congestion resulting from the LCTs.

\section{Application of the Proposed Methodology}

The Probabilistic Impact Assessment methodology is demonstrated using one real UK underground, residential LV network (Fig. 4) for the four LCTs under analysis. The main features of the 7 feeders of this network (supplied by a single $750 \mathrm{kVA} 11 \mathrm{kV} / 400 \mathrm{~V}$ transformer) are presented in Table I. The voltage at the busbar is considered to be $241 \mathrm{~V}$ phase-toneutral (1.05p.u.). This provides similar room for voltage rise and drop for the studied LCTs, allowing a fair comparison. 


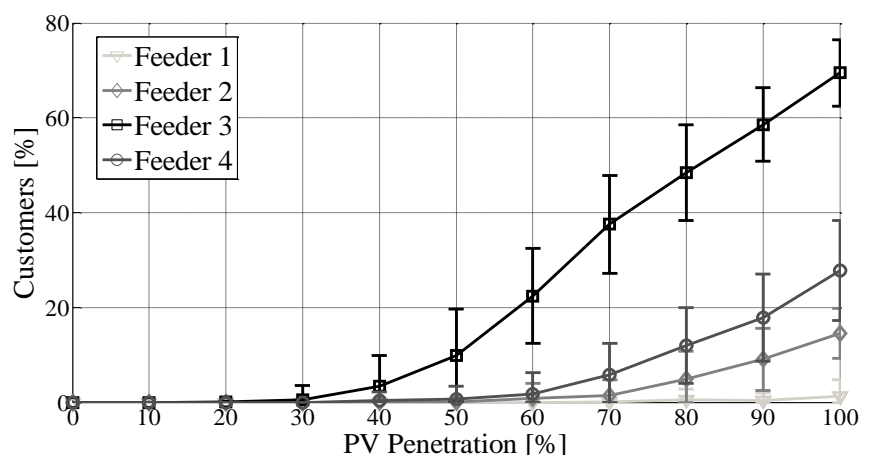

Fig. 5. Percentage of customers with voltage problems - PV Case

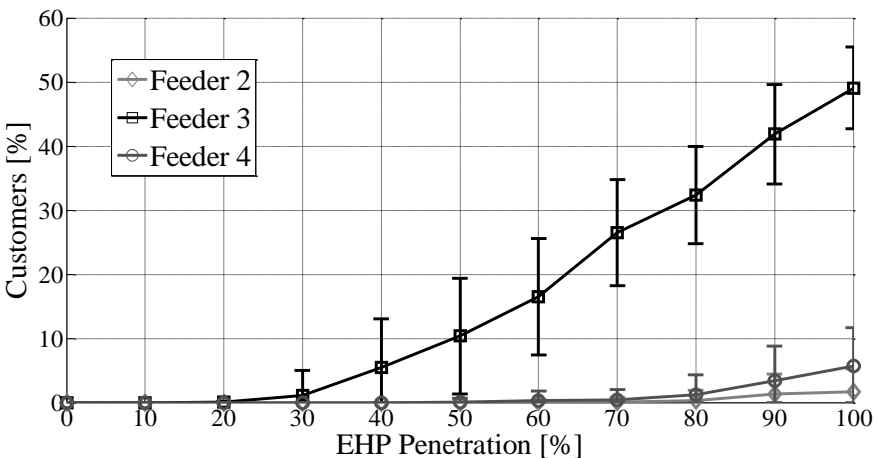

Fig. 6. Percentage of customers with voltage problems - EHP Case

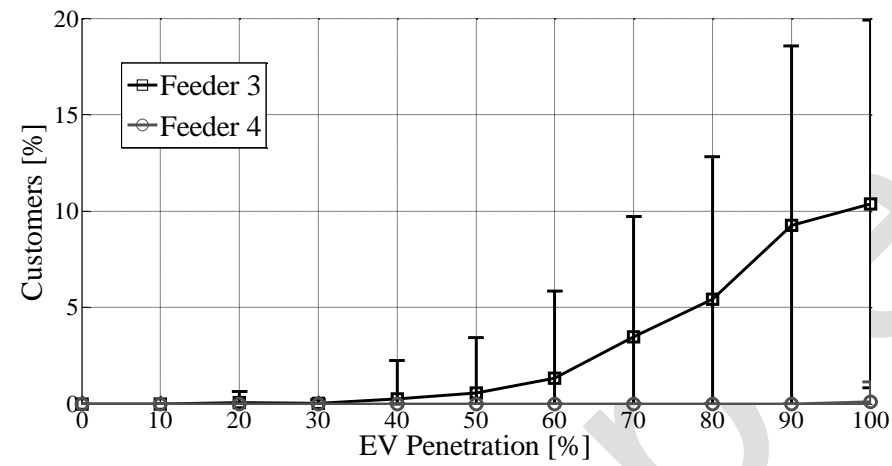

Fig. 7. Percentage of customers with voltage problems - EV Case

During minimum demand voltages across the feeder can be considered close to the $1.05 \mathrm{pu}$, allowing a voltage rise of extra $\sim 0.05$ p.u. During peak load, voltages across the feeder will be approximately 0.99p.u. (ENWL design criteria [32]), allowing a voltage drop of extra $\sim 0.05$ p.u.

\section{A. Voltage Problems}

The percentage of customers with voltage problems is calculated per simulation. These results are presented in Fig. 5 to Fig. 7 for each LCT considering the average value +/- one standard deviation (only feeders with problems are shown).

In the PV case (Fig. 5), four feeders have problems (voltage rise) at different penetration levels. The magnitude of problems for a particular penetration level varies per feeder. Thus, for feeders 3 and 4, the problems start at penetrations of 30 and $40 \%$, respectively. On the other hand, the $\mu$ CHP case does not experience any voltage (rise) issue.

EHPs (Fig. 6) start producing voltage (drop) problems also at $30 \%$ of penetration level. However, the magnitude of these problems across the different penetration levels is lower than that of the PV case. In fact, only feeder 3 has in average more

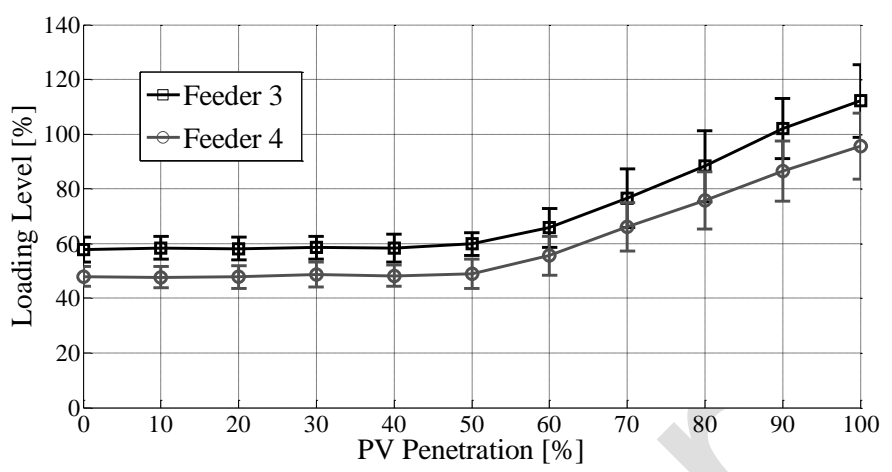

Fig. 8. Loading Level at the head of the feeder $-\mathrm{PV}$ Case

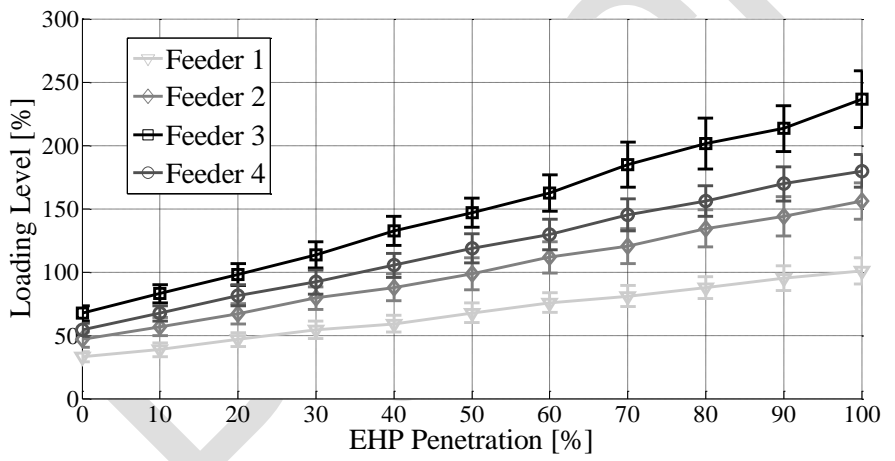

Fig. 9. Loading Level at the head of the feeder-EHP Case

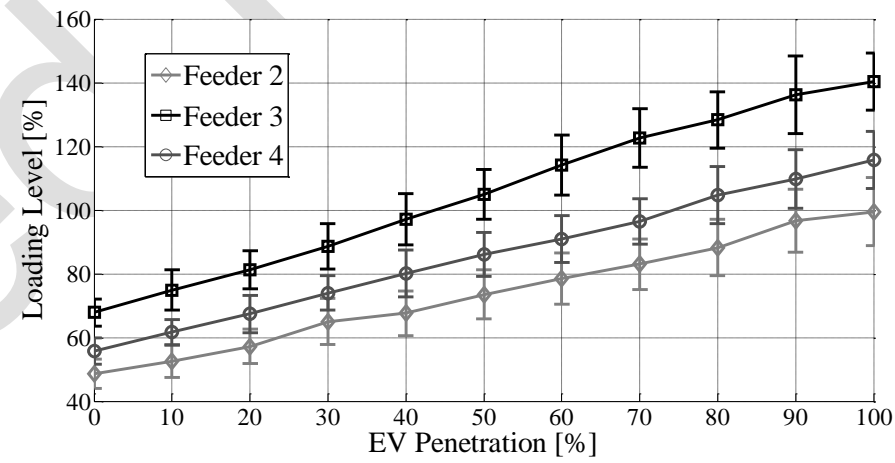

Fig. 10. Loading Level at the head of the feeder - EV Case

than $10 \%$ of the customers with voltage issues. For the EV case (Fig. 7), only feeder 3 presents significant problems. This, however, happens at much higher penetrations than the previous LCTs. Indeed, customer voltages in 6 out of the 7 feeders are unlikely to be affected even at $100 \%$ penetration.

Although this analysis is limited to one LV network, it is possible to observe that the feeders with few customers and relative short lengths (feeders 5, 6 and 7) do not present voltage issues in any of the cases. Conversely, the longest feeders with more customers (feeders 3 and 4) present problems for each LCT (except $\mu$ CHP). These findings help understanding and quantifying the potential LCT impacts. However, to truly capture those impacts on different types of real LV feeders, a multi-feeder analysis is carried out in section VII.

\section{B. Thermal Problems}

\section{1) Feeder Level}

The average loading level +/- one standard deviation (from the 100 simulations per penetration level for each LCT) at the head of the feeder is presented in Fig. 8 to Fig. 10 for the feeders with issues. The loading level almost increases linearly 
for the EHP and EV cases. The $100 \%$ of loading level for the EHPs (Fig. 9) is reached in average at 20, 40, 50 and $100 \%$ of penetration in feeders 3, 4, 2 and 1, respectively. In comparison, the same level is reached at higher penetrations for the EVs (Fig. 10): 50, 80 and $100 \%$ of penetration level for feeders 3, 4 and 2. For both cases, it can be seen that if all households adopt this new type of loads, then reinforcements will be needed in at least three feeders.

In the case of the generation technologies, the loading level behaves differently. The $\mu \mathrm{CHP}$ case does not present congestion problems (therefore no figure is presented). In fact, the loading level decreases when the penetration level increases. This happens because the local generation is coincident with (and also lower than) the electricity consumption. On the other hand, in the PV case (Fig. 8), the loading level decreases until $30-40 \%$ of penetration level and then starts to increase. The initial reduction is due to the local generation in the feeder, but this is not significant because the coincidence between the generation and peak demand is low (maximum PV injection is at noon and peak load occurs during the evening). Once the local generation is higher than the local consumption, the feeder starts exporting electricity to the upstream system.

From the findings above, it can be observed that those feeders with a few customers (feeders 5, 6 and 7) do not reach the maximum loading level in any of the studied cases. In fact, only the ones with more loads (feeders 3 and 4) exceed the rating capacity in all LCTs (except $\mu \mathrm{CHP}$ ). This highlights the need to extend this analysis to multiple real LV feeders.

\section{2) Transformer Level}

The results for the loading level of the transformer for each LCT are shown in Fig. 11. This metric behaves similarly to that of the feeder level. In fact, the transformer loading level rises almost linearly with the EHP and EV. It also has the same behavior in the PV and $\mu \mathrm{CHP}$ cases.

\section{ProbabiLISTIC ANALYSIS}

Given the statistical nature of this assessment, the analysis presented in section $\mathrm{V}$ can be extended. Indeed, the probability of having technical issues can be used to determine whether a given LCT penetration level, that could potentially produce a problem, is acceptable. In other words, by quantifying this probability, the DNO might conclude that it is feasible to accept penetration levels that represent low probabilities of technical problems instead of resorting to significant reinforcements or engaging in smart grid solutions.

\section{A. Cumulative Distribution Function}

From the Monte Carlo analysis, two cumulative distribution functions $(\mathrm{CDF})$ can be extracted per feeder and penetration level, one for each metric. For voltage issues, let $X$ be the percentage of customers with voltage problems. Thus, the corresponding CDF allows quantifying the probability to have at least $x \%$ of the customers with voltage problems. For example, the CDF for feeder 3 considering the PV case is presented in Fig. 12. It can be seen that the probability of having more than $10 \%$ of customers with voltage problems is around 0.4 at $50 \%$ of penetration level and 0.85 at $60 \%$ of penetration level.

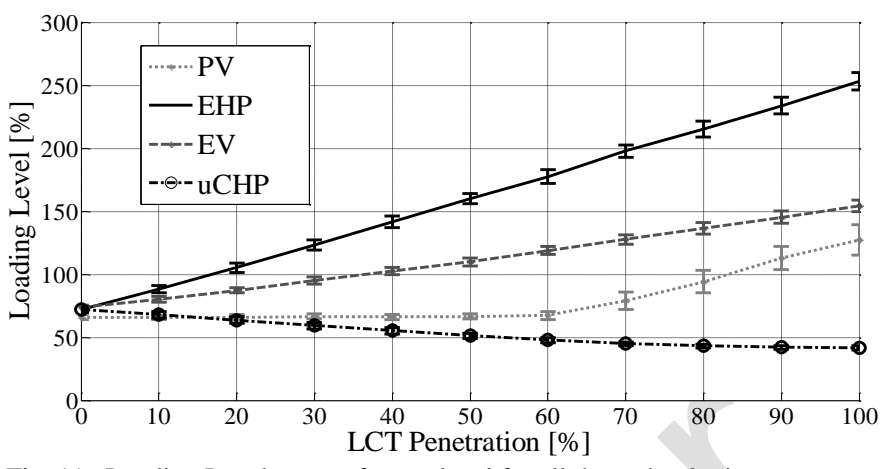

Fig. 11. Loading Level at transformer level for all the technologies

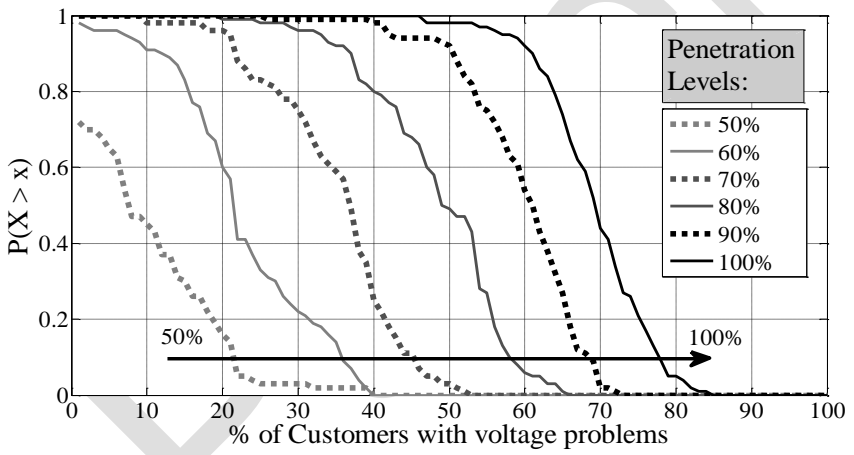

Fig. 12. CDF of voltage problems for feeder 3, PV case

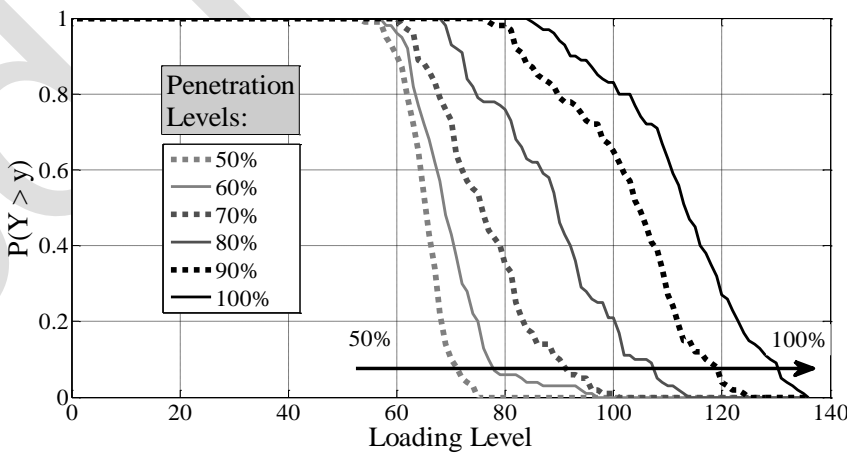

Fig. 13. CDF of thermal problems for feeder $3, \mathrm{PV}$ case

For thermal problems, let $Y$ be the loading level at the head of the feeder. This CDF represents the probability to have a loading level higher than $y \%$. For illustration purposes, Fig. 13 presents these CDFs (feeder 3, PV case). There, the probability to have more than $100 \%$ of loading level is about 0.2 and 0.6 for $80 \%$ and $90 \%$ of penetration levels, respectively.

\section{B. Likelihood of Voltage Problems}

In terms of the acceptance of a potential issue, a DNO can decide that is facing a problem only if the probability to have more than, for instance, $1 \%$ of the customers with voltage problems is equal or higher than a certain threshold. Hence, if the DNO does not want to accept any potential problem then it can set this value to zero, i.e., problems will be considered to start at soon as one of the simulations presents a voltage issue. In contrast, if the DNO is able to accept some level of potential problems, the threshold can be set to a higher value. For instance, Fig. 14 indicates the average percentage of customers with voltage problems $+/$ - one standard deviation for the EHP case on feeder 3, and the probability to have more than $1 \%$ of customers with voltage problems per penetration level. 
Hence, if the DNO does not accept any potential problem, then the issues start at $20 \%$ of penetration level (probability equal to 0.01). If the DNO sets the threshold at 0.05 , then the problems can be considered to start at $30 \%$ of penetration level (probability equal to 0.12 ). It is interesting to observe that in this example above $70 \%$ of penetration level always there are at least $1 \%$ of customers with voltage issues.

\section{Likelihood of Thermal Problems}

A similar analysis can be done for the loading level to decide when asset congestion (loading level higher than 100\%) is considered a problem or not. For instance, Fig. 15 presents the EV impacts on feeder 3 and the probability to have a loading level higher than $100 \%$ per penetration level.

If a conservative approach is adopted by the DNO, then the problems can be considered to start at $20 \%$ of penetration level (probability equal to 0.005). Nonetheless, typically, DNOs will allow certain level of overload in their assets. Therefore, it could be decided that problems are considered when congestion happens with a probability higher than 0.05 , resulting in a higher penetration of $30 \%$ (Fig. 15). Note that beyond $70 \%$ of EV penetration, the capacity of this feeder is always exceeded.

\section{Multi-FeEdER ANALYSIS}

In order to deeply explore the LCT impacts and their stochastic nature, and to extent the findings from the previous sections, the proposed Probabilistic Impact Assessment methodology is now applied to $128 \mathrm{LV}$ feeders considering the four LCTs (PV, EHPs, $\mu$ CHP and EVs). Furthermore, two sensitivity cases are included in this section to investigate the effects of a more conservative 0.95 inductive power factor for the EHP and EV technologies. No sensitivity analysis is carried out for the generation technologies (PV and $\mu \mathrm{CHP}$ ) given that unity power factor is already a conservative case (i.e., maximum active power injection).

The implemented feeders are located in the North West of England and are owned and operated by Electricity of North West Limited (ENWL). They have been modelled and validated from GIS data [33]. Hence, the real topology, conductor characteristics, customer locations, and phase connections are fully considered. In terms of the distribution of connections among the phases in this 128 feeders, the average percentage of customers in each phase (and corresponding standard deviation) is $34.6 \%(6.8 \%), 33.2 \%(6.2 \%)$ and $32.2 \%(6.02 \%)$ for phase $\mathrm{A}, \mathrm{B}$ and $\mathrm{C}$, respectively. This work has released the main characteristics of all the network models in [18].

In terms of computational time, the analysis of the 128 feeders for a single LCT, 11 penetration levels ( $0 \%$ to $100 \%$ ) and 100 simulations each, is carried out in about 16 hours on a desktop PC with Intel ${ }^{\circledR}$ Core TM i5-2400 3.10 GHz and 4 GB of RAM, i.e., about 7.5 minutes per feeder.

\section{A. General Analysis of LCT Impacts}

The Monte Carlo approach allows quantifying the technical problems from different LCT penetrations as well as determining their corresponding likelihood. Hence, a feeder is considered to have a voltage problem if the probability of having

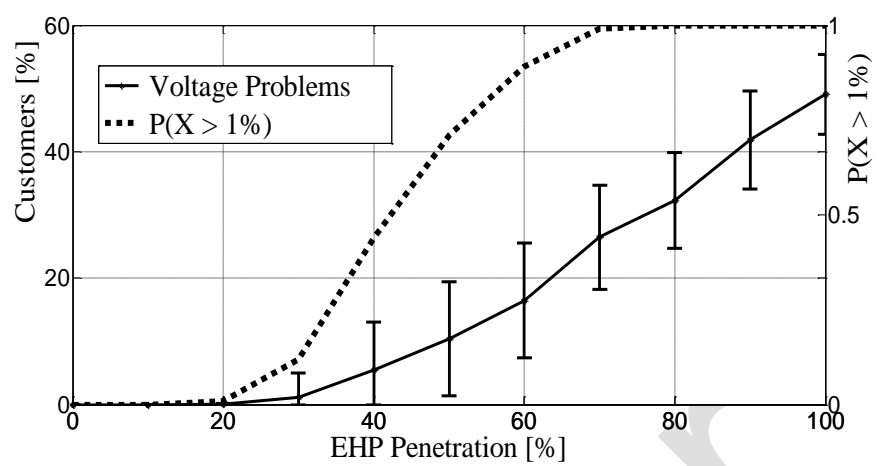

Fig. 14. Voltage problems and probability for feeder 3, EHP case

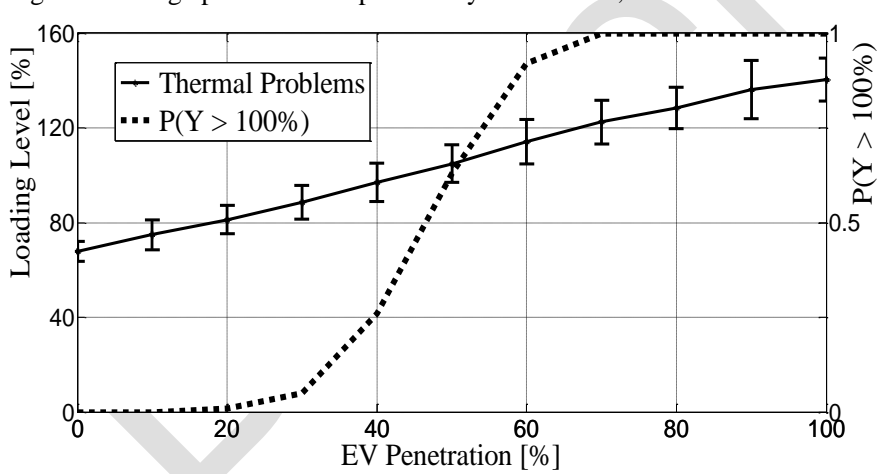

Fig. 15. Thermal problems and probability for feeder 3, EV case

more than $1 \%$ of customers with voltage problems $(X)$ is higher than a certain threshold $\alpha$, i.e., $P(X \geq 1) \geq \alpha$. This threshold can be set by the DNO according to its own acceptance of potential problems. Similarly, a feeder is considered to have a thermal problem if the probability of having a loading level $(Y)$ above the $100 \%$ of the rating capacity is higher than $\alpha$, i.e., $P(Y>100) \geq \alpha$. Thus, for a given LCT penetration, if $\alpha$ is set by the DNO to zero, the problems are considered to appear if at least in one of the simulations there is a problem. In contrast, if $\alpha$ is set to 0.05 , the problems are considered if at least in $5 \%$ of the simulations problems do occur.

\section{1) Feeder Level Impacts}

By using the previous considerations, the percentages of feeders that present voltage problems or thermal problems for at least one of the penetration levels (from 10 to $100 \%$ ) are illustrated in Fig. 16 for the most conservative threshold $(\alpha=$ $0)$. In the PV case, $45 \%$ of the feeders experience voltage problems and $17 \%$ exceed the rating capacity. In the EHP case, the percentage of feeders with voltage and thermal problems is 30 and $52 \%$, respectively. The adoption of an inductive power factor of 0.95 slightly increases the percentage of feeders with voltage problems to $33 \%$ and with congestion issues to $53 \%$. About only $3 \%$ of the feeders present problems in the $\mu \mathrm{CHP}$ case and these problems are exclusively related to voltage rise. For the EV case, the percentage of feeders with voltage problems is $18 \%$ and with thermal problems is $32 \%$.

A conservative power factor also results in more feeders with voltage problems (22\%) but remains the same for congestion problems (32\%). Fig. 16 also shows that the percentage of all feeders that experience a technical problem (voltage and/or thermal) is equal or slightly larger than that of the predominant problem. This is because those feeders will in most cases 
have the other problem (if any) at a higher penetration.

In addition, Table II presents the percentage of feeders with voltage and/or thermal problems for two different thresholds $(\alpha=0, \alpha=0.05)$. It is clear that a more conservative (lower) threshold results in more feeders with problems. For instance, in the case with $\alpha=0.05$, there are in average $14 \%$ and $16 \%$ less feeders with voltage and thermal problems, respectively, than those with $\alpha=0$. Thus, if a DNO is unable to accept any degree of potential problems, then measures will need to be taken in more feeders to ensure that possible technical issues are avoided. One finding from this analysis is that feeders with less than 25 customers (a total of 38, i.e., 30\%) do not present any problem with any LCT penetration. This is important as it highlights that concerns or potential preventive measures from DNOs should not be focused on this type of feeders.

For the feeders experiencing problems at some penetration level, Table III shows the percentage of those that experiences one technical problem (voltage or thermal) before the other for the two different thresholds $(\alpha=0, \alpha=0.05)$. The "bottleneck" for most of the feeders in the PV case is voltage. In fact, $98 \%$ of the feeders experience voltage problems first (for $\alpha=0$ ). Voltage problems also occur first in the $\mu \mathrm{CHP}$ case but this is limited to only $3 \%$ of all the feeders. For the EHP cases, the problems are triggered mainly by thermal issues $(70 \%$ for unity power factor and $75 \%$ for a 0.95 power factor). In the EV cases, also the thermal problems start before than those related to voltages. Indeed, about $65 \%$ of the feeders present thermal problems first for $\alpha=0$.

The above analysis shows that the first technical problem is different by LCT. For generation technologies (PV and $\mu \mathrm{CHP}$ ) the main problem is voltage rise whereas for the new loads (EHP and EV) the main problem is, but not exclusively, congestion. As a result, a single solution that can help with a particular LCT will not necessarily be useful for a different one.

\section{2) Transformer Rating Analysis}

The extra demand or reverse power flows from high penetrations of LCTs can also exceed the thermal limit of the MV/LV transformer. To analyze this, the loading level of those transformers is calculated for the 25 studied networks.

Table IV shows the percentage of transformers overloaded for at least one of the penetration levels for each LCT and for the thresholds $\alpha=0$ and $\alpha=0.05$. It is possible to observe that the $\mu$ CHPs do not produce problems at the transformer level. Furthermore, Table IV highlights that the EHP cases result in a more significant number of congested transformers (72\% for both cases and thresholds). This is higher than the percentage of feeders with problems (around half of them, Table II and Fig. 16), i.e., in the case of EHPs, transformers are likely to be the assets to be replaced first.

\section{B. Occurrence of the First Problems per LCT at Feeder Level}

The previous section gives a general assessment about the proportion of feeders and transformers with technical issues for each LCT at some penetration level. To provide further insights, this section presents the histograms of the penetration level at which voltage and thermal problems start. This penetration level is determined using (1) where Q is the set of pen-

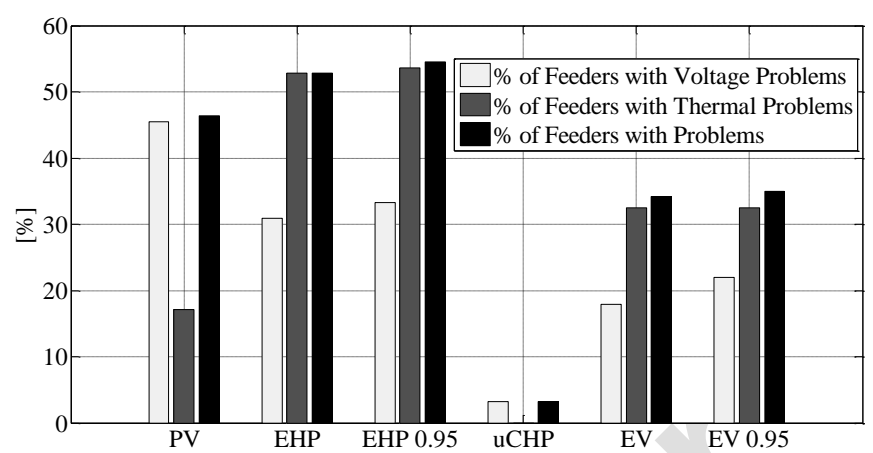

Fig. 16. Feeders with technical problems per technology $(\alpha=0)$

TABLE II

$\%$ OF FEEDER WITH PROBLEMS

\begin{tabular}{l|c|c|c|c}
\hline \multirow{2}{*}{ LCT } & \multicolumn{2}{|c|}{$\alpha=0$} & \multicolumn{2}{c}{$\alpha=0.05$} \\
\cline { 2 - 5 } & $\begin{array}{c}\text { Voltage } \\
\text { Problems }\end{array}$ & $\begin{array}{c}\text { Thermal } \\
\text { Problems }\end{array}$ & $\begin{array}{c}\text { Voltage } \\
\text { Problems }\end{array}$ & $\begin{array}{c}\text { Thermal } \\
\text { Problems }\end{array}$ \\
\hline PV & 45.5 & 17.0 & 39.0 & 13.8 \\
\hline EHP & 30.8 & 52.8 & 25.2 & 47.9 \\
\hline EHP 0.95 & 33.3 & 53.6 & 28.4 & 47.9 \\
\hline$\mu$ CHP & 3.2 & 0.0 & 3.2 & 0.0 \\
\hline EV & 17.8 & 32.5 & 15.4 & 25.2 \\
\hline EV 0.95 & 21.9 & 32.5 & 16.2 & 26.8 \\
\hline
\end{tabular}

TABLE III

FIRST TECHNICAL ISSUE PER LCT FOR FEEDERS WITH PROBLEMS

\begin{tabular}{l|c|c|c|c}
\hline \multirow{2}{*}{ LCT } & \multicolumn{2}{|c|}{$\alpha=0$} & \multicolumn{2}{c}{$\alpha=0.05$} \\
\cline { 2 - 5 } & $\begin{array}{c}\text { Voltage } \\
\text { Issues First }\end{array}$ & $\begin{array}{c}\text { Thermal } \\
\text { Issues First }\end{array}$ & $\begin{array}{c}\text { Voltage } \\
\text { Issues First }\end{array}$ & $\begin{array}{c}\text { Thermal } \\
\text { Issues First }\end{array}$ \\
\hline PV & 98 & 2 & 100 & 0 \\
\hline EHP & 30 & 70 & 19 & 81 \\
\hline EHP 0.95 & 25 & 75 & 24 & 76 \\
\hline$\mu$ CHP & 100 & 0 & 100 & 0 \\
\hline EV & 35 & 65 & 41 & 59 \\
\hline EV 0.95 & 35 & 65 & 40 & 70 \\
\hline
\end{tabular}

TABLE IV

$\%$ OF TRANSFORMERS WITH PROBLEMS

\begin{tabular}{c|c|c|c|c|c|c}
\hline LCT & PV & EHP & $\begin{array}{c}\text { EHP } \\
0.95\end{array}$ & $\mu$ CHP & EV & $\begin{array}{c}\text { EV } \\
0.95\end{array}$ \\
\hline$\alpha=0$ & 20 & 72 & 72 & 0 & 28 & 32 \\
\hline$\alpha=0.05$ & 20 & 72 & 72 & 0 & 20 & 20 \\
\hline
\end{tabular}

etration levels and $\mathrm{p}_{\mathrm{i}}$ is the penetration level $\mathrm{i}$.

$$
\begin{gathered}
p_{1} \equiv\left\{\min \left(p_{i}\right) \in Q \mid P\left(Y\left(p_{i}\right)>100\right)>\alpha\right\} \\
p_{2} \equiv\left\{\min \left(p_{i}\right) \in Q \mid P\left(X\left(p_{i}\right) \geq 1\right)>\alpha\right\}
\end{gathered}
$$

Hence, $\mathrm{p}_{1}$ and $\mathrm{p}_{2}$ represent the first penetration levels with thermal and voltage problems, respectively. Fig. 17 shows the percentage of feeders that have the first occurrence of thermal problems in a particular penetration level, $p_{1}$, for each LCT and considering $\alpha=0$. This figure shows that for the PV case most of the feeders with thermal problems have the first congestion issues at higher penetration levels ( $70 \%$ and above). In contrast, in the EHP cases most of the feeders with thermal issues present problems at early penetration levels (20-40\%). Finally, in the EV cases, the first thermal problems are more or less spread across penetration levels. A similar analysis for $p_{2}$ is presented in Fig. 18. There, it is possible to observe that for all the LCTs a higher proportion of feeders experience the first voltage problems at lower penetration levels (mainly concentrated between 20 and 50\%).

From the above analysis it is possible to determine for each 
LCT the percentage of feeders with technical problems, the type of problem (voltage or congestion), and the penetration level when this happens. With this information a ranking of the LCTs that lead to the first occurrence of problems in each feeder can be produced. It is found that the most problematic technology is the EHP. In fact, this technology produces technical issues before than any other LCT in $60 \%$ of the feeders mostly related to congestion ( $55 \%$ of the feeders). PV is the second most problematic, producing technical issues before any other LCT in $40 \%$ of the feeders (mainly voltage rise).

Depending on the LCT penetration projections of a given DNO, region or country, this information can be used to determine the most adequate deployment of mitigating actions. For instance, in the context of the UK, where PV installations are expected to grow faster than EHPs in the midterm (current number of EHPs represents only $0.02 \%$ of the households [34] and residential PV installations about 2\% [35]), this finding highlights that potential solutions due to voltage issues should be planned accordingly. It is important to note that the qualitative nature of this analysis remain the same for $\alpha=0.05$.

\section{MUlTi-FEEDER CORRELATION ANALYSIS}

To investigate why some feeders present problems earlier than others, a correlation analysis is carried out. For this, in addition to the Probabilistic Impact Assessment, different parameters from the 128 feeders (such as length, number of customers, supplied area, etc.) are also calculated. By identifying the ones with the best coefficients of determination $\left(\mathrm{R}^{2}\right)$, it is possible to create lookup tables that can help DNOs to determine the hosting capacity of a given feeder.

\section{A. Definition of Parameters}

The physical feeder characteristics investigated are:

- Feeder Length. Total length of each feeder taking into account main and services cables.

- Customer Number. Total number of customers supplied per feeder.

- Initial Loading Level. Loading level (hourly maximum current divided by the ampacity) at the head of each feeder without any LCT.

- Main Path. Distance between the MV/LV transformer busbar and the furthest customer.

- Main Path Resistance. Sum of all series resistances (+ sequence) in the main path. Note that the average R/X ratio of the main paths in the 128 studied feeders is 3.9.

- Supplied Area. Total area supplied by the feeder. This area is estimated by calculating the convex hull that encloses all the feeder vertices.

- Total Resistance Aggregation. Sum of all cable resistances (+ sequence) in the feeder (including service cables).

- Supplied Perimeter. Length of the convex hull.

- Total Path Resistance. Sum of all Path Resistances between the busbar and each customer (2).

$$
T P R=\sum_{i=1}^{N} \text { Path Resistance }_{i}
$$

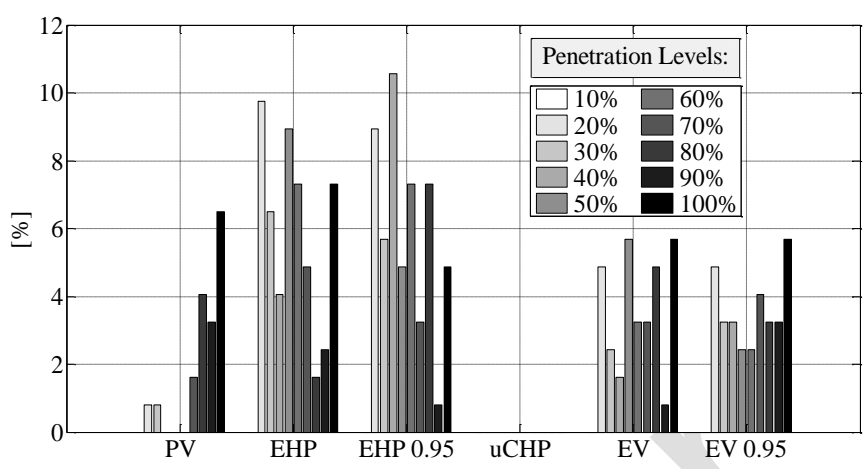

Fig. 17. First occurrence of thermal problems per technology $(\alpha=0)$

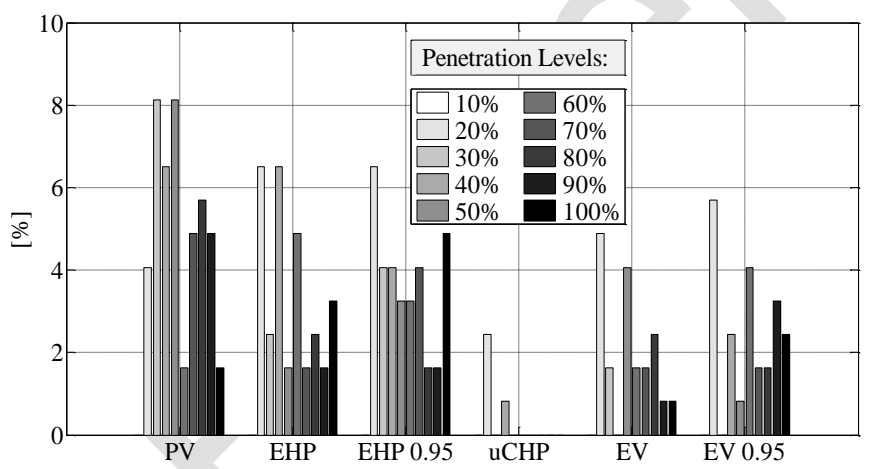

Fig. 18. First occurrence of voltage problems per technology $(\alpha=0)$

TPR is the Total Path Resistance, $N$ is the number of loads in each feeder, and the Path Resistance is the resistance between the busbar and the load $i$.

\section{B. Correlation Analysis}

The correlation analysis is carried out per LCT considering the parameters described above by plotting them against the penetration level at which problems start $\left(p_{\min }\right.$, calculated as in (3) considering voltage and thermal issues). A fitting process is then executed to calculate the corresponding coefficient of determination $\left(\mathrm{R}^{2}\right.$, where a perfect correlation results in 1$)$.

$$
p_{\text {min }} \equiv \min \left\{p_{1}, p_{2}\right\}
$$

Since about half of the feeders under analysis do not present problems for any of the simulations for many of the different penetration levels (up to $100 \%$ ), it is not possible to extract useful information from them. Therefore, additional penetration levels are investigated in this section. In total, 31 different penetration levels are explored ranging from $0 \%$ to $300 \%$ in steps of $10 \%$. This means, for instance, that a particular house can have multiple devices of the studied LCT (e.g., multiple EVs).

The investigation of penetration levels beyond $100 \%$ allows the identification of the penetration level that actually triggers a technical issue in the feeder so this valuable information can be included in the correlation analysis. To illustrate this correlation analysis, Fig. 19 presents the plot and fitted curve corresponding to the Customer Number considering the PV case. In this figure, where each dot represents one feeder, it can be observed that those feeders with more customers experience problems earlier than those with fewer customers. Although this finding is intuitive, this correlation might not be strong enough. In fact, the corresponding $\mathrm{R}^{2}$ is 


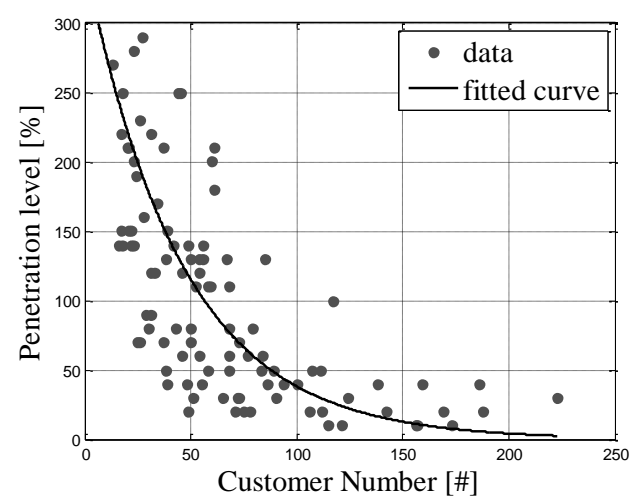

Fig. 19. Penetration Level versus Customer Number $-\mathrm{PV}$ case

TABLE V

$\mathrm{R}^{2}$ FOR EACH PARAMETER AND LCT

\begin{tabular}{l|c|c|c}
\hline Parameter / LCT & PV & EHP & EV \\
\hline Length & 0.73 & 0.71 & 0.69 \\
\hline Customer Number & 0.68 & 0.74 & 0.74 \\
\hline Initial Loading & $\mathbf{0 . 8 0}$ & $\mathbf{0 . 9 0}$ & $\mathbf{0 . 8 9}$ \\
\hline Main Path & 0.65 & 0.48 & 0.44 \\
\hline Main Path Res. & 0.60 & 0.46 & 0.41 \\
\hline Supplied Area & 0.67 & 0.55 & 0.55 \\
\hline Supplied Perimeter & 0.64 & 0.51 & 0.46 \\
\hline Total Resistance & 0.72 & 0.72 & 0.65 \\
\hline TPR & $\mathbf{0 . 8 9}$ & $\mathbf{0 . 8 5}$ & $\mathbf{0 . 8 3}$ \\
\hline
\end{tabular}

0.68. This means that for feeders with similar number of customers the PV penetration range at which problems start could be significantly large, and hence not conclusive.

The correlation analysis is applied to all the proposed parameters and LCTs, considering the two thresholds for potential problems $\alpha=0$ and $\alpha=0.05$. Given that the results for both thresholds are similar, only the corresponding $\mathrm{R}^{2}$ for the conservative case $(\alpha=0)$ are presented in Table V. Here, it is possible to observe that the parameters with the strongest coefficients of determination are the Initial Loading Level and the Total Path Resistance. The former gives an idea of how assets are used at present (without any LCT) and therefore can help anticipating the occurrence of thermal problems. The latter, on the other hand, embeds the overall resistance of the feeders, and therefore has a good relationship with the possible voltage drops/rises. In both cases, the average coefficient of determination among the three technologies is about 0.86 . As an example, the Total Path Resistance can be observed in Fig. 20 for the PV case. By comparing Fig. 19 and Fig. 20, it is possible to observe the reduction in sparseness which results in an improvement of $\mathrm{R}^{2}$ from 0.68 to 0.89 .

The $\mu$ CHP is not considered in this analysis because this technology leads only to problems in just four feeders, i.e., a sample too small for correlation analysis.

\section{Lookup Tables}

The previous correlation analysis identifies the main feeder characteristics with the strongest relationship $\left(\mathrm{R}^{2}\right)$ with the first occurrence of a technical problem. The information contained in this analysis can be translated into lookup tables for DNOs to estimate the LCT hosting capacity of a particular feeder. These tables can be used to produce preliminary and quick assessments before carrying out detailed analyses.

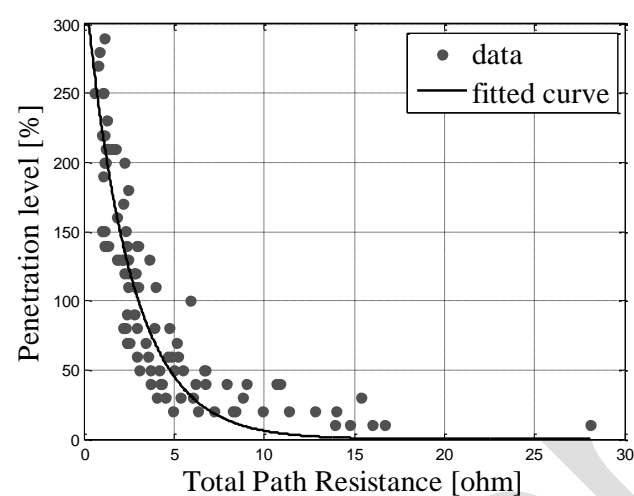

Fig. 20. Penetration Level versus TPR - PV Case

TABLE VI

LOOKUP TABLES: PV HOSTING CAPACITY $\%(\alpha=0)$

\begin{tabular}{|c|c|}
\hline \multicolumn{2}{|c|}{ Customer Number } \\
\hline Interval & 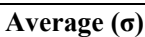 \\
\hline $0-24$ & N/A \\
\hline $25-57$ & $>100(80)$ \\
\hline $58-90$ & $77(55)$ \\
\hline $91-123$ & $39(27)$ \\
\hline $124-156$ & $25(13)$ \\
\hline $157-223$ & $24(13)$ \\
\hline
\end{tabular}

\begin{tabular}{|c|c|}
\hline \multicolumn{2}{|c|}{ TPR } \\
\hline Interval & Average (б) \\
\hline $0-2.1$ & N/A \\
\hline $2.2-6.4$ & $84(42)$ \\
\hline $6.5-10.7$ & 34 (13) \\
\hline $10.8-15.0$ & $25(12)$ \\
\hline $15.1-19.4$ & $15(10)$ \\
\hline $19.5-28.1$ & $10(0)$ \\
\hline
\end{tabular}

To illustrate the production of one possible lookup table, Table VI presents the estimated PV hosting capacity based on the customer number and the TPR of a feeder. This information is taken from the corresponding correlation analysis (Fig. 19 and Fig. 20) and divides the parameter values in six segments. The first segment contains those feeders without any technical problem and the rest are distributed uniformly (up to the maximum value of the parameter). For each of the segments, the average and standard deviation is calculated among the corresponding feeders.

For instance, Table VI shows that those feeders with customers between 124 and 156 can host in average $25 \%$ of PV penetration. The same process can be repeated for each LCT and, particularly, for those parameters that present the best coefficients of determination. As shown in Table V, given that the $\mathrm{R}^{2}$ of the TPR is larger than that of the customer number, the PV penetration has smaller variations (lower standard deviations), i.e., more accurate estimates. Thus, to adopt these lookup tables a compromise has to be made by DNOs between having a straight forward parameter (e.g., customer number, feeder length) that leads to lower accuracy or one that requires more effort to compute (e.g., TPR, initial loading level) but estimates better the LCT hosting capacity of a feeder.

\section{CONCLUSIONS}

This work proposed a Probabilistic Impact Assessment methodology based on a Monte Carlo approach to analyze low carbon technologies in residential LV networks. Realistic 5min time-series profiles were implemented for loads, PV systems, EHPs, EVs and $\mu \mathrm{CHP}$ units. One hundred simulations are considered per penetration level (as percentage of houses with a LCT) in order to cater for the corresponding uncertainties (i.e., size, location, behavior of loads and LCTs). Daily impacts are quantified using two key metrics: the percentage 
of customers with voltage problems, and the loading level at the head of the feeder and the transformer.

The creation of realistic LCT profiles allowed comparing their average potential effects. The average peak demand or generation for 100 profiles was found to be 3.0, 2.2, 1.2 and $0.6 \mathrm{~kW}$ for PV, EHP, EV and $\mu \mathrm{CHP}$, respectively. Given that the average peak residential load is around $1.0 \mathrm{~kW}$, these figures give a clear indication of the potential issues.

The methodology was in first place demonstrated and explained in detail by using a real three-phase four-wire LV distribution network. Then, it was applied to 128 residential underground feeders. Given the probabilistic nature of the results, these were analyzed considering the probability of having technical problems (voltage and/or congestion) higher than a given value to be defined by the decision maker (e.g., a DNO) to represent their own acceptance of potential problems. Two values were examined in this work: 0 (zero acceptance of problems) and 0.05 (more than 5\% of the Monte Carlo simulations for a given penetration level must have a problem).

Although the consideration of two different thresholds affects the magnitudes of the results, the conclusions trends are similar. The PV technology produced problems in about $47 \%$ of the feeders. EHPs produced problems in about $53 \%$ of the feeders and the EVs triggered problems in $34 \%$ of the feeders. Almost no impacts were produced by $\mu \mathrm{CHP}$ units. Consequently, about half of the studied feeders are capable of having $100 \%$ of the houses with a given LCT. Additionally, it was found that feeders with less than 25 customers $(30 \%$ of the studied feeders) did not present any problem for any of the LCTs. This finding can be used by DNOs to focus efforts on those feeders with larger number of customers or even to adopt new design policies.

Among the feeders with problems for a particular LCT, it was established that the first problem to occur depends on the technology type. Considering a zero acceptance of potential problems, problems due to PV are mostly caused by voltage rise (98\% of the cases). In contrast, with EHPs and EVs problems are mainly due to congestion (above 70 and 60\%, respectively). This highlights that a solution that could help with a particular LCT will not necessarily mitigate the impacts from a different one.

A ranking analysis carried out to determine the LCT that produces problems at the earliest penetrations revealed that both EHPs and PV systems are in the top place: $60 \%$ of the feeders with problems will see early issues due to EHPs whilst for $40 \%$ it will be due to PV systems. Thus, based on the LCT penetration projections for a particular area, the most effective mitigating actions could be determined in advance.

To investigate why some feeders present problems earlier than others, a correlation analysis was performed exploring the relationship between several parameters (feeder length, number of customers, supplied area, etc.) and the first occurrence of problems. With a zero acceptance of potential problems, the individual parameters with the best coefficient of determination $\left(\mathrm{R}^{2}\right)$ were the Total Path Resistance (TPR) and the Initial Loading Level: average of 0.86 among the three LCT.

Finally, it was shown that the findings from the correlation

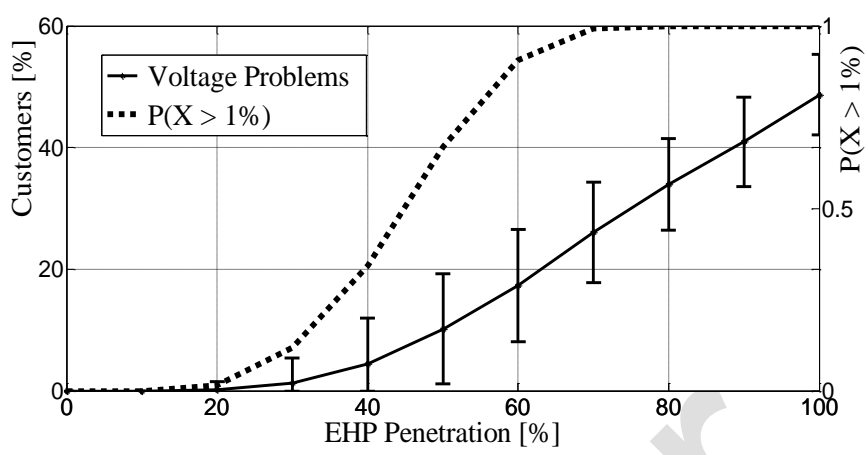

Fig. 21. Voltage problems and probability for feeder 3, EHP case - 1000 sim

TABLE VII

TOTAL SQUARE ERROR (TSE) AND TIME PER NUMBER OF SIMULATIONS

\begin{tabular}{c|c|c|c|c|c|c|c}
\hline Sim: & 25 & 50 & 75 & 100 & 400 & 600 & 1000 \\
\hline TSE & 0.049 & 0.014 & 0.005 & 0.002 & 0.001 & 0.0006 & n/a \\
\hline $\begin{array}{c}\text { Time } \\
{[\mathrm{min}]}\end{array}$ & 5.3 & 10.5 & 15.7 & 20.9 & 83.5 & 125.1 & 208.6 \\
\hline
\end{tabular}

can be translated into practical lookup tables. This can help DNOs carrying out preliminary estimations of the LCT hosting capacity of a particular feeder without the need of detailed analyses.

\section{APPENDIX}

Within the proposed Monte Carlo-based approach, one hundred simulations were performed in each penetration level. This number was chosen considering the trade-off between computational time and accuracy of the results. To exemplify this effect, different simulation numbers (i.e., 25, 50, 75, 100, 400, 600 and 1000) were analyzed for one specific feeder (feeder 3 in Fig. 4). The simulation time for each of the cases is presented in Table VII. It is possible to observe that computational time increases linearly with the number of simulations carried out.

In addition, to illustrate the difference in the results for different simulation numbers, Fig. 21 shows the EHP voltage impacts and the probability to have more than $1 \%$ of customers with problems using 1000 simulations. This figure can be compared with Fig. 14 (100 simulations). The main difference between these two cases is that the probability at $20 \%$ of penetration level increases from 0.01 to 0.016 (1000 simulations). Nonetheless, in both cases the relevant problems start at $30 \%$ of penetration level. The comparison between these probability distributions can be done using the Total Square Error (TSE) with respect to the probability distribution calculated from the 1000 simulations. These results are summarized in Table VII, showing that the case with 100 simulations is a good compromise because leads to results almost as accurate as those from 1000 simulations but at a tenth of the time.

\section{REFERENCES}

[1] European Comission, "Europe 2020 targets," 2007. [Online]. Available: http://ec.europa.eu/europe2020/europe-2020-in-anutshell/targets/index_en.htm.

[2] Her Majesty Government, "The UK renewable energy strategy," 2009. [Online]. Available: https://www.gov.uk/government/publications/theuk-renewable-energy-strategy. 
[3] British Standards Institution, "BS EN 50160: Voltage characteristics of electricity supplied by public distribution systems," 2000.

[4] F. Demailly, O. Ninet, and A. Even, "Numerical tools and models for Monte Carlo studies of the influence on embedded generation on voltage limits in LV grids," IEEE Trans. Power Syst., vol. 20, no. 3, pp. 2343-2350, 2005.

[5] K. Clement-nyns, E. Haesen, and J. Driesen, "The impact of charging plug-in hybrid electric vehicles on a residential distribution grid," IEEE Trans. Power Syst., vol. 25, no. 1, pp. 371-380, 2010.

[6] R. Leou, C. Su, and C. Lu, "Stochastic analyses of electric vehicle charging impacts on distribution network," IEEE Trans. Power Syst., vol. 29, no. 3, pp. 1055-1063, May 2014.

[7] P. Chen, R. Salcedo, Q. Zhu, D. Czarkowski, Z. Jiang, V. Spitsa, Z. Zabar, and R. E. Uosef, "Analysis of voltage profile problems due to the penetration of distributed generation in low-voltage," IEEE Trans. Power Syst., vol. 27, no. 4, pp. 2020-2028, 2012.

[8] R. Tonkoski, D. Turcotte, and T. H. M. El-Fouly, "Impact of high PV penetration on voltage profiles in residential neighborhoods," IEEE Trans. Sustain. Energy, vol. 3, no. 3, pp. 518-527, Jul. 2012.

[9] M. S. Elnozahy and M. M. A. Salama, "A comprehensive study of the impacts of PHEVs on residential distribution networks," IEEE Trans. Sustain. Energy, vol. 5, no. 1, pp. 332-342, 2014.

[10] C. Gonzalez, J. Geuns, S. Weckx, T. Wijnhoven, P. Vingerhoets, T. De Rybel, and J. Driesen, "LV distribution network feeders in Belgium and power quality issues due to increasing PV penetration levels," in IEEE PES Innovative Smart Grid Technologies Conference Europe (ISGT), 2012.

[11] F. Vallée, V. Klonari, T. Lisiecki, O. Durieux, F. Moiny, and J. Lobry, "Development of a probabilistic tool using Monte Carlo simulation and smart meters measurements for the long term analysis of low voltage distribution grids with photovoltaic generation," Int. J. Electr. Power Energy Syst., vol. 53, pp. 468-477, 2013.

[12] M. Thomson and D. G. Infield, "Network power-flow analysis for a high penetration of distributed generation," IEEE Trans. Power Syst., vol. 22, no. 3, pp. 1157-1162, 2007.

[13] A. Navarro-Espinosa and P. Mancarella, "Probabilistic modeling and assessment of the impact of electric heat pumps on low voltage distribution networks," Appl. Energy, vol. 127, pp. 249-266, Aug. 2014.

[14] M. Akmal, B. Fox, D. J. Morrow, and T. Littler, "Impact of high penetration of heat pumps on low voltage distribution networks," in IEEE PES PowerTech 2011, 2011.

[15] K. Qian, C. Zhou, M. Allan, and Y. Yuan, "Modeling of load demand due to EV battery charging in distribution systems," IEEE Trans. Power Syst., vol. 26, no. 2, pp. 802-810, May 2011.

[16] R. Torquato, Q. Shi, W. Xu, and W. Freitas, "A Monte Carlo simulation platform for studying low voltage residential networks," IEEE Trans. Smart Grid, pp. 1-11, 2014.

[17] A. Hoke, R. Butler, J. Hambrick, and B. Kroposki, "Steady-state analysis of maximum photovoltaic penetration levels on typical distribution feeders," IEEE Trans. Sustain. Energy, vol. 4, no. 2, pp. 350-357, 2013.

[18] A. Navarro-Espinosa and L. F. Ochoa, "Low carbon solution project: 'Network Dissemination," 2015. [Online]. Available: http://www.enwl.co.uk/about-us/the-future/lcnf-tier-1-projects/lowvoltage-network-solutions.

[19] A. Navarro, L. F. Ochoa, and D. Randles, "Monte Carlo-based assessment of PV impacts on real UK low voltage networks," in IEEE Power and Energy Society General Meeting, 2013.

[20] I. Richardson, M. Thomson, D. Infield, and C. Clifford, "Domestic electricity use: A high-resolution energy demand model," Energy Build., vol. 42, no. 10, pp. 1878-1887, Oct. 2010.

[21] Office for National Statistics UK, "Families and households, 2001 to 2011," Statistical Bulletin, 2012. [Online]. Available: http://www.ons.gov.uk/ons/dcp171778_251357.pdf.

[22] The University of Manchester, "The Whitworth Meteorological Observatory." [Online]. Available: http://www.cas.manchester.ac.uk/restools/whitworth/.

[23] EvoEnergy, "Solar Cell Efficiency," 2014. [Online]. Available: http://www.evoenergy.co.uk/solar-panels/our-technology/pv-cellcomparison/.

[24] P. Richardson and J. Taylor, "Impact of electric vehicle charging on residential distribution networks: An Irish demonstration initiative," in 22 International Conference on Electricity Distribution, 2013.
[25] Carbon Trust, "Micro-CHP Accelerator - Final Report," 2011. [Online]. Available: http://www.carbontrust.com/resources/reports/technology/micro-chpaccelerator.

[26] Calorex, "Domestic Heat Pumps - Low carbon solutions for heating and hot water," 2013. [Online]. Available: http://www.calorex.com/heat-pumps/documents/DomHeatv.4.pdf.

[27] R. Dugan and T. Mcdermott, "An open source platform for collaborating on smart grid research," in IEEE Power and Energy Society General Meeting, 2013.

[28] E. Jaeger, A. Du Bois, and B. Martin, "Hosting capacity of LV distribution grids for small distributed generation units, referring to voltage level and unbalance," in 22 International Conference on Electricity Distribution, 2013.

[29] B. Bletterie, S. Kadam, M. Stifter, R. Pitz, and A. Abart, "Optimisation of LV networks with high photovoltaic penetration - balancing the grid with smart meters," in IEEE PowerTech, 2013.

[30] P. Richardson, D. Flynn, and A. Keane, "Impact assessment of varying penetrations of electric vehicles on low voltage distribution systems," in IEEE Power and Energy Society General Meeting, 2010.

[31] UK Parliament, "The Electricity Safety, Quality and Continuity Regulations," $2003 . \quad$ [Online]. Available: http://www.legislation.gov.uk/uksi/2002/2665/pdfs/uksi_20022665_en. pdf.

[32] Electricity North West Limited, "Code of Practice 226: Low Voltage Network Design," 2011

[33] T. Gozel and L. F. Ochoa, "Deliverable 3.2: 'Production of Validated Networks," 2013.2 [Online]. Available: http://www.enwl.co.uk/docs/default-source/future-lowvoltage/university-of-manchester-appendix-e1.pdf?sfvrsn=2.

[34] Office of Gas and Electricity Markets UK, "Domestic renewable heat incentive: The first 10,000 domestic RHI accreditations," 2014. [Online]. Available: https://www.ofgem.gov.uk/ofgempublications/90603/drhi1st10000.pdf.

[35] Office of Gas and Electricity Markets UK, "Feed in Tariff: Annual Report 2012-13," $2013 . \quad$ [Online]. Available: https://www.ofgem.gov.uk/ofgempublications/85271/fityear3annualreport-finaledition.pdf. 